\title{
DÉTENTE E DÉTENTES NA ÉPOCA DA GUERRA FRIA (DÉCADAS DE 1960 E 1970)
}

\author{
DÉTENTE AND DÉTENTES DURING THE COLD WAR \\ (1960s AND 1970s)
}

\author{
Sidnei J. Munhoz* \\ José Henrique Rollo**
}

Resumo: Este artigo tem como objetivo o estudo da Détente durante a Guerra Fria. Isto será efetuado pela análise de diferentes modelos analíticos utilizados por especialistas para examinar aquele período histórico. Desse modo, neste trabalho, o desenvolvimento da noção de détente durante a Guerra Fria e as diferentes détentes sublinhadas por diferentes perspectivas serão objeto de escrutínio. Para a consecução desses objetivos, o artigo explora as diferentes características da chamada Détente Francesa, da Ostpolitik e da détente Estadunidense Soviética.

Palavras-chave: Guerra Fria; Détente;

Abstract: This article has as subject the study of Détente during the Cold War. It will be done by the analysis of different frameworks used by scholars to examine that historical period. Thus, in this work, the development of a notion of Détente during the Cold War and the different détentes highlighted by diverse points of view will be subject of scrutiny. To do that, the article explores the main characteristics of the so-called French Détente, the Ostpolitik, and the US-USSR Détente.

Keywords: Cold War; Détente;

\footnotetext{
** Doutor em História Econômica (USP) e Professor Associado do Departamento de História e do Programa de Pós-graduação em História da UEM, Maringá, Paraná, Brasil. Agradeço ao CNPq pela Bolsa Produtividade em Pesquisa que possibilitou o desenvolvimento destes estudos. E-mail:sidneimunhoz2010@gmail.com

** Doutor em História Comparada (UFRJ) e Professor Adjunto do Departamento de História da UEM, Paraná, Brasil. E-mail: zrollo@uol.com.br
} 
Entre aproximadamente 1947 e 1989-1991, EUA e URSS competiram pela construção e consolidação de esferas de influência, lastreados em diferentes projetos políticos. Foi o período da Guerra Fria, época que é vista, predominantemente, sob a perspectiva de um mundo dividido por um conflito bipolar a envolver dois blocos organizados e dinamizados pelas duas únicas superpotências globais. Essa imagem, bastante verossímil, merece ser matizada de forma adequada. Se, de um lado, a Guerra Fria significou a intensificação de conflitos em escala planetária, de outro, ela produziu, após a fase inicial, certa estabilidade, além de padrões toleráveis e previsíveis de confronto. Os dois Estados confrontaram-se de forma indireta por intermédio dos países que compunham as suas respectivas esferas de influência, mas, ao mesmo tempo, impediram que conflitos regionais escapassem ao controle e se transformassem em guerras de dimensões mundiais. Assim, produziram certa estabilidade mundial mesmo que sob o risco e a ameaça de um permanente confronto nuclear.

A busca de estabilidade, a definição de padrões toleráveis de conflito e, ao mesmo tempo, a criação de canais para a negociação, deram origem a uma fase do conflito que foi denominada détente, distensão ou, ainda, desanuviamento. Uma fórmula jornalística para defini-la foi produzida por André Fontaine:

[...] os vinte anos transcorridos após o fim da prova de força que engajou, em outubro de 1962, Kruschev e Kennedy a propósito dos mísseis de Cuba. O medo de ambas as partes foi tal que elas se prometeram de tudo fazer para evitar que doravante se reencontrassem a beira do abismo. Foi assim que a uma fase de "tensão" extrema se sucedeu uma fase de indiscutível "distensão"

Para o então editor-chefe do diário parisiense Le Monde, o marco temporal mais recuado do período estava em 1962. Contudo, ele mesmo observou, mais adiante, que os anos transcorridos entre a morte de Stalin, em março de 1953, e os acontecimentos de 1956 na Hungria (intervenção soviética) e no Egito (intervenção franco-britânico-israelense durante a assimchamada crise de Suez) também conheceram um "degelo" que bem poderia ser denominado "distensão" 2 ). As hesitações do experiente jornalista francês indicam-nos que, no que diz respeito à détente, há fortes polêmicas quanto à datação dessa fase bem como quanto ao significado que se pode atribuir ao próprio termo. Convém, então, discutir melhor essas questões.

Em um estudo de grande valia, embora, como é comum entre os pesquisadores anglo-saxões, limitado à bibliografia em língua inglesa, Brian White $^{3}$ estabeleceu as principais variações nos usos profissionais da palavra détente. Segundo ele, podemos compreendê-la em três claves, basicamente. 
Primeira: como uma "condição" (que pode adquirir basicamente três significados: um "período histórico", uma fase de "prelúdio a uma entente", "uma ilusão"). A definição acima citada expressa essa variante. Segunda: como um "processo" que poderá ser ou não ser consumado em algum momento, transformando-se em condição permanente. Em 1974, ao afirmar diante de uma comissão do Senado estadunidense que détente seria "um processo contínuo, não uma condição final que foi ou poderá ser realizada em algum ponto específico no tempo", Henry Kissinger, exemplificou claramente essa segunda acepção ${ }^{4}$. Terceira: como uma "política" (ou seja, uma forma de ação das elites dirigentes de diferentes países em diferentes momentos visando reduzir os riscos de confronto, aumentar sua segurança e ampliar suas oportunidades comerciais). A definição proposta por Richard Stevenson adequa-se bem a essa terceira clave. Para ele, trata-se "do processo de alívio de tensão entre estados cujos interesses são tão radicalmente divergentes que a reconciliação é inerentemente limitada"s.

Apesar dessas diferenças no campo léxico do termo, no período em consideração prevaleceu, regra geral, uma noção de distensão a envolver quase que somente os EUA e a União Soviética. Podem-se elencar e discutir numerosos motivos para essa espécie de hegemonia cognitiva, mas esse não é o momento para fazê-lo. Basta apontar que, durante a Guerra Fria, as mentalidades coletivas foram como que colonizadas por uma percepção binária da ordem geopolítica global, condição da qual poucos acadêmicos conseguiram efetivamente escapar. Esse macrodispositivo semiológico (produzido pelos mais diversos atores locucionais e iconográficos dotados dos mais diversos interesses) simplificava as visões do mundo e gerava explicações automáticas para todos os eventos relevantes em matéria de política internacional. É certo que ele teve muita dificuldade em capturar e enquadrar a China e as pretensões de terceiras e quartas vias de desenvolvimento político que emergiram no então-chamado Terceiro Mundo. Porém, foi vitorioso em suas linhas gerais. Daí a recorrente negligência no tratamento dos interesses específicos dos Estados aliados de ambas as potências e, em particular, a pouca importância dada ao protagonismo de suas elites dirigentes na configuração daquele Globo que a percepção binária hegemônica simplificava em demasia.

Ainda hoje, a compreensão dos mecanismos que geraram os processos de détente na época da Guerra Fria se vê em boa medida prisioneira - ao menos quando avaliamos a literatura de divulgação que orienta estudantes, professores não especializados e jornalistas - daquele macrodispositivo semiológico. Assim, pouca atenção é dada ao fato de que esse período de relaxamento nas tensões entre as superpotências foi precedido por uma distensão a envolver a Europa Ocidental e a URSS. Em especial, pode se delinear a existência de uma distensão entre a França e a URSS e outra a enredar a Alemanha Ocidental e o mundo comunista ${ }^{6}$. Neste artigo pretendemos explorar distintas dimensões e 
dialogar com interpretações ancoradas em diferentes matizes analíticos desse processo. Adotamos como ancoragem conceitual uma articulação entre dois dos sentidos mais amplos da expressão détente apontados por Brian White: aceitamos que ela nomeia uma fase da Época da Guerra Fria durante a qual diferentes políticas destinadas a relaxar as tensões foram perseguidas por elites dirigentes alinhadas em de ambos os blocos. Em diversas ocasiões, como se verá mais adiante, a conduta estratégica daquelas elites nacionais, que eram vistas pelo prisma do macrodispositivo semiológico hegemônico como permanentemente subalternizadas por Washington e por Moscou, foi capaz de estabelecer pautas amplas de ação e interferir decididamente no curso dos processos históricos.

Não existe consenso quanto à periodização da détente como fase da Guerra Fria. No entanto, há duas posturas que sobressaem. A primeira é que data seu início do final de 1962, após a chamada crise dos mísseis cubanos, quando foram iniciadas conversações entre as diplomacias dos EUA e da URSS, objetivando a negociação da proibição dos testes nucleares, a limitação dos arsenais e a criação de mecanismos ágeis de comunicação entre os líderes das duas potências, de forma a evitar que um incidente de proporções menores pudesse desencadear uma hecatombe nuclear. A segunda, que é a mais aceita, abrange o período que se estende de 1969 a 1979, caracterizado por relações de cooperação e de competição simultâneas, sem implicar a ausência de conflitos, mas o estabelecimento de padrões aceitáveis para a solução das divergências ${ }^{7}$. Neste artigo, pautamo-nos pela primeira vertente de periodização, assumindo que a segunda cobre um espaço de tempo no qual o processo de distensão desencadeado anos antes adquiriu sua etapa de maior estabilidade.

\section{BIPOLARIDADE, CRISE DA BIPOLARIDADE E EMERGÊNCIA DA DÉTENTE.}

A bipolaridade que se definiu durante a década de 1950 - facilitada pelo declínio imperial da Inglaterra e da França, mas posta em questão pela ascensão da China à condição de potência nuclear - viu-se ameaçada pela irrupção de uma série de processos de alcance global nas duas décadas seguintes. A disputa entre soviéticos e estadunidenses pelo controle da Ásia e da África ao longo do processo de descolonização encontrou sua contrapartida na emergência do terceiro-mundismo. Os movimentos correspondentes na Europa foram as mobilizações anti-nucleares e as lutas urbanas. Na América Latina, foi a expansão de ditaduras e da resistência armada. É bastante verossímil a hipótese de que a Détente sovieto-estadunidense foi uma estratégia das superpotências para buscarem o relaxamento das tensões e manterem a ordem constituída no pós-guerra diante de movimentos que continham elevado potencial de instabilidade. 
As rivalidades entre os EUA e a URSS desde a Revolução Bolchevique foram congeladas durante a II Guerra Mundial. Quando esta terminou, velhos conflitos retornaram e novos emergiram em decorrência das disputas relativas ao Leste Europeu e, posteriormente, do anúncio da Doutrina Truman e do Plano Marshall. Naquele período, as situações mais críticas ocorreram em função da crise no Irã e no Azerbaijão, da demanda soviética de acesso aos estreitos do Mar Negro, da tomada do poder pelos comunistas na Tchecoslováquia (1948), do bloqueio de Berlim (1948) e da Guerra da Coréia (1950-1953).

Essa fase crítica foi sucedida por outra de gradual reconhecimento das respectivas áreas de influência. Ainda sob Stalin, os soviéticos defenderam, em 1952, a busca de uma coexistência pacífica e propuseram a reunificação da Alemanha como Estado neutro, mas o Ocidente nunca levou a sério a ideia. Em 1953, novos fatores ampliaram as possibilidades de negociação entre os dois blocos então formados: a eleição de Dwight Eisenhower para a presidência dos EUA, a morte de Stalin e o fim da Guerra da Coréia. Outro passo importante foi a saída dos soviéticos da Áustria em 1955, após a negociação da neutralidade do país, embora no mesmo ano fosse fundado o Pacto de Varsóvia como resposta à entrada da Alemanha Ocidental na OTAN ${ }^{8}$.

Em adição, o discurso de Nikita S. Krushchev no XX Congresso do PCUS, em fevereiro de 1956, alimentou novas expectativas de aproximação. No entanto, naquele mesmo ano, a eclosão dos conflitos na Polônia, a intervenção da França, Grã-Bretanha e Israel no Egito e a invasão da Hungria por tropas do Pacto de Varsóvia aumentaram a instabilidade internacional. No final da década de 1950, houve nova reaproximação. Em 1959, pela primeira vez um dirigente máximo da URSS visitou os EUA. Krushchev e Eisenhower firmaram um tratado que definiu a Antártida como área livre de armamentos nucleares. Tais encontros foram precursores da détente ${ }^{9}$.

Tudo indicava uma gradativa melhora nas relações entre EUA e URSS, quando a Revolução Cubana em 1959 e a derrubada de um avião de espionagem estadunidense (U2), que invadira o espaço aéreo soviético em 1960, produziram novos impasses. Provavelmente, o maior perigo de uma guerra nuclear ocorreu quando, após as tentativas de invasão de Cuba por forças treinadas e apoiadas pelos EUA, os soviéticos iniciaram a instalação de 24 mísseis nucleares na ilha. Em outubro de 1962, quando os EUA perceberam o fato, deram um ultimato. Após um crescente de tensões a implicar a possibilidade real da ocorrência de uma guerra nuclear, foram iniciadas negociações entre as diplomacias das duas superpotências. Daí resultou o recuo soviético com a retirada dos mísseis instalados em Cuba. Cabe notar que mísseis dos EUA haviam sido instalados pouco antes na Turquia (precisar), e que parte deles foi retirada como resultado dos acordos para encerrar o conflito. A assim conhecida "crise dos mísseis cubanos" estimulou a criação de mecanismos de negociação para evitar uma possível guerra nuclear, como 
a instalação do telefone vermelho entre Moscou e Washington, e o acordo de 1963 que proibia testes nucleares submarinos, atmosféricos ou no espaço. A deposição de Krushchev em 1964 não promoveu significativas alterações nas relações entre os dois países ${ }^{10}$.

\section{DIFERENTES ABORDAGENS}

Outras abordagens exploram a temática de forma complexa, mas ao mesmo tempo singular. Jussi M. Hanhimäki entende que houve uma Détente europeia que precedeu e teve continuidade após o fim da Détente estadunidense-soviética. $\mathrm{O}$ autor entende que essa perspectiva de análise não retira a importância da distensão a envolver os EUA e a URSS, mas é uma decorrência do fato de que a Europa esteve sempre no centro da Guerra Fria. Acrescenta que a Détente europeia resultou dos desafios dos países do chamado Velho Continente ao excesso de bipolaridade do período anterior. Sublinha que, em parte, essa distensão foi proveniente de perspectivas nacionalistas como as colocadas por De Gaulle, que pretendia conferir à França maior status no cenário internacional, ou, mais importante ainda, dos desafios postos pelo projeto de Ostpolitik perseguido por Willi Brandt ${ }^{11}$.

Hanhimäki defende ainda a tese de que as crises geradas pela construção do muro de Berlim em 1961 e a crise dos misseis cubanos geraram novas percepções da Guerra Fria nos dois lados da Europa dividida. Ressalta que durante a crise dos misseis, nenhum governo europeu, nem mesmo o britânico, foi consultado pelos EUA. Indica que os aliados do Pacto de Varsóvia também não foram consultados por Krushchev. Naquele contexto, era muito real a sensação de que se algo desse errado, a Europa seria alvo de retaliações. Assim, as lideranças europeias começaram a enfrentar o dilema de uma Europa dividida, dependente economicamente dos EUA ou da URSS, com a presença de tropas estrangeiras, e ameaçada por arsenais nucleares de dois grandes rivais que se defrontavam pelo controle do continente.

Ainda, os governantes europeus perceberam que naquele contexto, a Europa passava a ocupar um papel secundário no cenário internacional. Afinal, com o agravamento da crise no Vietnã, das lutas anticoloniais na África, dos desafios postos pela China que procurava trilhar um caminho próprio e desafiava tanto o modelo estadunidense quanto soviético, e outras tensões, como aquelas emergidas nos conflitos do Oriente Médio, as potências dedicavam pouca atenção à Europa, que embora dividida permanecia estável ${ }^{12}$.

Por fim, o autor adota o conceito de pericentrismo de Tony Smith para interpretar as ações dos parceiros menores que, do seu ponto de vista, procuram explorar as tensões e as rivalidades das grandes potências com o objetivo de defender os seus interesses domésticos e regionais. Hanhimäki entende que nas décadas de 1960 e 1970 muitos atores europeus procuraram defender os seus interesses nacionais ou buscaram a integração econômica e 
política ou ainda uma combinação desses fatores ${ }^{13}$.

De forma a retomar a questão da Guerra Fria global e da Détente sovieto-estadunidense, é adequado resgatar o modelo analítico traçado por Fred Halliday. Para ele a Guerra Fria compreende o período de 1946 a 1953. Naquele período, as relações diplomáticas entre as duas potências centrais foram congeladas e praticamente inexistiram. Segundo esse autor, nas duas esferas de influência edificadas pelas duas potências rivais, observou-se o aumento dos sistemas de controle internos e da repressão doméstica; a expansão das forças militares e dos arsenais bélicos, nucleares ou não; a intensificação da propaganda; os conflitos entre capitalismo e comunismo se estenderam ao chamado Terceiro Mundo, por meio de situações revolucionárias. sublinha-se que conflitos no interior dos blocos estavam subordinados ao conflito global. Para Halliday, essa fase chegou a termo em 1953 com o fim do segundo mandato de Truman como presidente dos EUA e com a morte de Stalin, uma vez que as duas personagens que galvanizavam o conflito saíram de cena.

Entre aproximadamente 1953 e 1969, segundo Halliday, ocorreu um período de Equilíbrio Oscilatório, quando as duas potências centrais buscaram alguma forma de aproximação e de solução dos conflitos. Contudo, essa fase haveria sido entremeada por momentos de extrema tensão, como ocorreu, por exemplo, em decorrência da invasão da Hungria por tropas do Pacto de Varsóvia (1956), da Revolução Cubana (1959), da derrubada do U-2 (avião espião dos EUA) sobre o território soviético (1960), da tentativa de invasão de Cuba por forças treinadas e apoiadas pelos EUA (1961), com a crise da construção do Muro de Berlim (1961) e a crise dos mísseis cubanos (1962). Para o autor, esse período foi seguido pela Détente (1969-1979).

Não obstante, a Détente haveria se esgotado pelos conflitos emergentes no Terceiro Mundo, pelas dificuldades de aplicação doméstica dos acordos, principalmente nos EUA em decorrência da crescente oposição a essa política que era mostrada como frágil e incapaz de fazer frente à ameaça soviética. Ainda para Halliday, a Détente chegou ao fim e foi seguida pela Segunda Guerra Fria que teria se iniciado ainda ao final do governo Carter, em grande medida como uma resposta às críticas à Détente e haveria se consolidado com a chegada de Reagan ao poder, quando então novamente o conflito adquire características bastante próximas da I Guerra Fria ${ }^{14}$.

O modelo analítico de Halliday é bem estruturado e possui coerência interna, contudo, observa-se uma outra possibilidade interpretativa que, de um lado, incorpora a análise do historiador britânico, mas, de outro, entende o conflito como uma única Guerra Fria e as divisões muito bem delineadas por Halliday, como fases desse mesmo conflito.

\section{A DÉTENTE FRANCESA}

Talvez, Charles de Gaulle (1890-1970) tenha sido, no início da década 
de 1960, o primeiro a empregar o termo Détente com uma concepção mais claramente definida de uma política relacionada à Guerra Fria. O líder francês ao empregar o termo procurava caracterizar uma política de relaxamento das tensões entre a França e a URSS. De fato, antes dele os seus conterrâneos Pierre Mendès France e Edgar Faure empregaram o termo de forma genérica Mendès France havia levado a questão do desarmamento e da Détente para as Nações Unidas em 1954.

Com esses objetivos, seu sucessor, Edgar Faure demandou a convocação de uma reunião dos dirigentes das quatro potências em 1955. Apesar dessas sinalizações, o posicionamento da França durante a Quarta República ainda não possuía as características de desafio à ordem bipolar instituída pelo sistema da Guerra Fria ${ }^{15}$.

A definição de um posicionamento diferenciado por parte da França foi produto do conflito entre os interesses das elites dirigentes francesas e as condições impostas pela bipolaridade da Guerra Fria e a consequente supremacia dos EUA na Europa Ocidental. Em decorrência, muitas vezes os interesses específicos da França colidiam com os interesses globais da potência dominante. Entre meados da década de 1950 e o final da década seguinte houve uma perceptível erosão nas relações entre a França e os EUA. Quando a última encontrou dificuldades na contenção às lutas pela independência nacional no Vietnã, os EUA passaram gradativamente a dar suporte aos franceses. Contudo, as lideranças francesas acreditavam que muitas vezes os EUA feriam os seus interesses ou não ofereciam o necessário apoio.

O ápice desse desgaste se deu com a derrota da França na batalha de Dien Bien Phu, em 1954. Pouco depois, os governantes franceses se sentiram humilhados pela posição dos EUA e da União Soviética que obrigaram França, Grã Bretanha e Israel a interromperem as suas ações contra o Egito, quando Nasser nacionalizou o Canal de Suez. Na continuidade, cresceu na França a percepção de que os EUA haveriam colocado em questão a sua legitimidade no conflito da Argélia e que até mesmo haveriam estimulado os nacionalistas argelinos. Para Bozo, o conflito em relação ao Canal Suez foi o ponto de partida para que a França iniciasse a busca de um caminho autônomo que rompesse com as amarras impostas pela Guerra Fria (BOZO, 2010, p. 164).

Após a sua saída do governo em 1946, ao longo de uma década De Gaulle foi um crítico implacável da fragilidade da Quarta República e da postura subordinada da França como um parceiro menor dos EUA no cenário da Guerra Fria. Assim, o seu retorno ao governo em 1958 demarcou uma virada na política externa francesa. De Gaulle intencionava reconquistar uma posição de potência para a França e ao mesmo tempo garantir a estabilidade interna. Após a solução do conflito argelino que deixava a França em uma situação indefensável, o presidente francês tratou de delinear uma política externa autônoma. Para De Gaulle, a reconquista pela França de um status de 
potência não estava desassociada da transformação do sistema global. Dessa forma, ele tratou de delinear uma política de longa duração que partia da avaliação de que a situação internacional tal qual estava configurada naquele momento era passageira. Para ele, na União Soviética, o comunismo não era definitivo e cedo ou tarde a Rússia ressurgiria como uma potência tradicional. Ele acreditava que Stalin mascarava com a ideologia antigos projetos dos Tzares. Assim, De Gaulle acreditava que as regiões dominadas pela URSS procurariam um caminho para a sua independência. Acreditava ainda que o predomínio dos EUA na Europa também era uma situação temporária, pois assim que a URSS recuasse, os EUA tenderiam a retornar às suas posições isolacionistas e o continente poderia reconquistar a sua autonomia ${ }^{16}$.

Essas divergências sobre as diretrizes implementadas por meio da Otan eram minimizadas pela existência de um inimigo comum (a URSS), que, de certo modo, contribuía para a manutenção da unidade da aliança e implicava a busca de solução para os problemas emergentes. A França, durante a presidência de Charles De Gaulle, insistia desde meados de 1958 na necessidade de se repensar a forma de condução da organização e criticava a suposta supremacia angloamericana existente na instituição. Em decorrência, adotou uma postura de criar mecanismos próprio de proteção, desenvolver sua própria defesa nuclear e por fim em 1966 se retirou do mecanismo militar da Otan 17 .

A princípio, De Gaulle concentrou as suas atenções na tentativa de redesenhar a aliança do Ocidente. Assim, em 1958, o presidente francês encaminhou um documento ao general Eisenhower, presidente dos EUA e ao primeiro ministro Britânico Harold McMillan, solicitando a criação de um diretório tripartite formado pelos EUA, Grã-Bretanha e França. A recusa da proposta francesa por Eisenhower e por seu sucessor, John F. Kennedy, levou De Gaulle a entabular um projeto no bojo da cooperação com a Alemanha que apontava em linhas gerais as bases da proposta de criação de uma Comunidade Econômica Europeia, com autonomia em relação aos EUA: o plano Fouche (1961-1962).

O plano embora derrotado em decorrência das divergências internas e da oposição dos EUA, demarcou o caminho da França em busca de uma posição autônoma frente aos EUA e da edificação de uma política externa que levasse ao relaxamento das tensões com a URSS. Para Bozzo, muitos dos pressupostos do plano Fouche se assemelhavam à perspectiva defendida por George F. Kennan, então já distante do centro da elaboração política externa dos $\mathrm{EUA}^{18}$.

Ao longo dos próximos anos, apesar do seu anticomunismo e das pesadas críticas que De Gaulle havia feito quando estava na oposição, responsabilizando a URSS e os comunistas pela Guerra Fria, o presidente francês manteve uma agenda bastante dinâmica com vistas a melhorar as 
relações com a URSS e com os países do Leste Europeu. Em paralelo, De Gaulle golpeou a lógica do mundo bipolar quando em 1966 retirou a França estrutura militar da Otan e em 1967 visitou Moscou com vistas a dirimir as tensões entre os dois países e estabelecer relações comerciais mais intensas ${ }^{19}$.

\section{A OSTPOLITIK}

De forma distinta de De Gaulle, os líderes da República Federal da Alemanha (RFA) não propugnavam mudanças globais. De fato, independente da coloração partidária, democrata cristã ou social democrata, Ludwig Erhard, Kurt Kiesinger e Willy Brandt buscaram cada um à sua forma um caminho mais independente para a RFA e inclusive começaram a estabelecer relações com os países do Leste da Europa, quando as políticas de Konrad Adenauer fracassaram em promover a reunificação da Alemanha.

Assim, as origens da Ostpolitik estão associadas à construção do Muro de Berlim, à ausência de um esforço claro do Ocidente e do fracasso da chamada doutrina Hallstein (a doutrina aprovada em 1955 considerava como um ato hostil à RFA o reconhecimento da RDA por qualquer outra nação) no sentido da reunificação da Alemanha ${ }^{20}$.

Naquele contexto, em 1963, ocorreu o veto francês ao ingresso da Grã Bretanha na Comunidade Econômica Europeia e a assinatura de um pacto de cooperação entre a Alemanha e a França. Essa situação inclusive produziu nos EUA o temor de que com a diminuição do receio de uma agressão soviética pudesse vir a ocorrer na Europa uma tendência à neutralidade o que poderia colocar em risco a própria Otan.

Brandt era o prefeito de Berlim quando o Muro foi construído. Impactado pelos efeitos da obra, e receoso de que implicasse a divisão em definitivo da Alemanha, começou a pressionar Konrad Adenauer e o presidente dos EUA, John F. Kennedy. Sem resultados concretos, nos anos seguintes Brandt amadureceu as suas propostas e se fortaleceu politicamente no seio do SPD (Partido da Social Democracia). Em 1966, com a crise do governo Erhard, Brandt estabeleceu uma aliança com a Democracia Cristã e se tornou chanceler e ministro das relações exteriores do governo Kiesinger. Foi nesse contexto que Brandt deu os primeiros passos em direção à construção de uma Ostpolitik que, literalmente, significa "Política Oriental" ou "Política do Leste".

Em 1967, a Alemanha estabeleceu relações com a Romênia e um acordo comercial com a Checoslováquia. Em janeiro do ano seguinte, o país estabeleceu relações com Iugoslávia. Naquele mesmo ano Kiesinger sinalizou que a Alemanha estava disposta a estabelecer relações com todos os vizinhos de forma a criar um clima político amistoso em toda a Europa. Kiesinger encaminhou ainda 16 propostas de cooperação com a Alemanha Oriental (RDA). No entanto, o governo da RDA exigia o pleno reconhecimento da 
Alemanha Oriental e o estabelecimento de relações diplomáticas entre os dois países.

Não obstante, Walter Ulbricht, chefe de governo da RDA, demandava adicionalmente que Berlim Ocidental fosse incorporada à Alemanha Oriental e que as duas nações tivessem representação na Organização das Nações Unidas (ONU). No entanto, essas negociações foram abruptamente interrompidas quando da invasão da Checoslováquia pelas tropas do Pacto de Varsóvia, em agosto de 1968. No ano seguinte uma coalização de forças liderada por Brandt ganhou as eleições e ele tornou-se o primeiro ministro ${ }^{21}$.

Em 1970, Brandt manteve duas reuniões de negociação com o premiê da RDA Willi Stoph. Na primeira, não houve resultados concretos, mas, no segundo encontro, ocorreram avanços significativos, quando Brandt contornou as exigências legais da RFA no sentido da existência de um único Estado alemão e, assim, aceitou a realidade de dois Estados no interior de uma única nação alemã. Brandt recebeu críticas da oposição e respostas frias da RDA. No entanto, em agosto do mesmo ano assinou com a URSS um pacto de não agressão. O pacto resolvia ainda uma série de pendências em termos de definição de fronteiras resultantes da II Guerra Mundial. Em Dezembro de 1970, assinou um acordo com a Polônia reconhecendo a linha Oder-Neisse como a fronteira ocidental da Polônia.

Das três potencias responsáveis pela administração de Berlim Ocidental, a França já mantinha apoio às políticas de Brandt. Para a Inglaterra, o apoio da RFA ao ingresso da Grã Bretanha na Comunidade Econômica Europeia era fundamental e, assim, não estava interessada em criar maiores óbices aos projetos de Brandt. Contudo, os EUA mantinham desconfianças em relação à Ostpolitik, mas Kissinger, principalmente, reconhecia que a doutrina Hallstein era anacrônica e que perdia apoio na RFA. Assim, entendeu que para manter o controle da situação seria melhor apoiar Brandt. Em agosto de 1971, França, Grã Bretanha, Estados Unidos e URSS assinaram um acordo quadripartite que estabelecia o direito irrestrito de locomoção dos alemães Ocidentais a Berlim Ocidental, permitia aos berlinenses ocidentais viajar para a RDA e determinava o status da cidade em relação à RFA.

A essa época, Brandt recebeu reconhecimento internacional, quando recebeu o Premio Nobel da Paz, pelos seus trabalhos no sentido de melhorar a relação entre as duas alemanhas e mais ainda entre a Europa Ocidental e o Mundo Soviético. Em 1972, as duas alemanhas assinaram tratados que normalizavam as relações entre os dois países e permitiam a reunificação de famílias que viviam separadas pelo Muro. Além disso, o acordo também definia alguns parâmetros para a libertação de prisioneiros. Brandt ainda firmou, em 1972, novos acordos na área econômica com a URSS e com a Romênia, e tratados de fronteira com a Checoslováquia no ano seguinte. (ARMS, 2010, p. 449). Contudo, a emergência de uma crise em 1974, quando 
um auxiliar direto (Gunter Guillaume) foi preso, após ser descoberto que era espião a serviço da RDA, levou à renúncia de Brandt e em parte significou o fim da Ostpolitik.

\section{A DÉTENTE ESTADUNIDENSE SOVIÉTICA OU SOVIETO- ESTADUNIDENSE}

Alguns autores entendem que tanto a definição da Ostpolitik de Willi Brandt quanto a Détente de Nixon-Kissinger foram, em grande medida, respostas aos desafios colocados pela política de distensão com a URSS implementada por De Gaulle e pela adoção de uma política externa francesa mais independente. Assim, apesar renúncia De Gaulle como uma decorrência dos eventos de maio de 1968, o seu legado no campo da construção de uma maior autonomia europeia frente aos EUA permaneceu.

No início da década de 1970, é perceptível que não apenas a França, mas a Grã Bretanha, a Alemanha e a Itália estão a estabelecer intensas relações comerciais coma URSS e com o Leste da Europa ${ }^{22}$. Assim, nos EUA, o próprio empresariado, anticomunista quase que por natureza, passou a avaliar que a postura de confronto implícita na política externa do país, resultava na perda de terreno comercial para essa nova Europa que apresentava um capitalismo dinâmico e em condições conquistar mercados na União Soviética e na Europa Oriental. O projeto de distensão de Nixon-Kissinger foi em parte produto da percepção de que o capitalismo estadunidense estava a perder terreno tanto para os aliados europeus quanto para o pujante capitalismo japonês que haviam sido reconstruídos sob os auspícios dos EUA.

Da perspectiva do governo Nixon a Détente era essencialmente uma estratégia realista para lidar com o desafio do poder soviético em um momento em que os EUA estavam a enfrentar um relativo declínio. Assim, Nixon e Kissinger planejaram essa política com o intento de alcançar basicamente três objetivos: buscar o controle de armas estratégicas e ao mesmo tempo criar mecanismos para manter uma balança estratégica favorável; mudar o foco da contenção da União Soviética pelos EUA, para levar a URSS à sua autocontenção; por fim, envolver a URSS em relações econômicas, tecnológicas e culturais, de forma a tornar o país mais dependente do Ocidente e assim menos disposto a agir de forma hosti123.

Para Schulzinger, a Détente de Nixon partia do reconhecimento de que havia um declínio relativo do poder estadunidense e de que havia o crescimento da multipolaridade. Em adição, Nixon entendia que os parceiros europeus estavam a buscar um caminho alternativo que lhes ampliasse as relações econômicas e reduzisse as tensões políticas com a União Soviética. Ainda, o então presidente estadunidense reconhecia a importância da soberania nacional e, desse modo, acreditava que a estabilidade global dependia em grande medida de que grandes potências como os EUA e a URSS não se envolvessem nas 
questões internas uma da outra ${ }^{24}$.

No entanto, Nixon encontrou dificuldades para implementar esse projeto político no interior da sociedade estadunidense. As resistências não estiveram restritas à oposição democrática, mas mesmo entre os republicanos e setores da sociedade civil organizada ${ }^{25}$. Assim, com o tempo houve um crescente de contestações à Détente. Uma das fontes de contestação foi exatamente que o respeito à soberania da União Soviética implicava o não questionamento da repressão aos dissidentes que, então, ocorria naquele país ${ }^{26}$. Assim, os defensores dos direitos humanos passaram a condenar de forma veemente essa política. Esse foi inclusive um tópico bastante explorado por Carter em sua campanha eleitoral vitoriosa contra a tentativa de reeleição de Gerald Ford, após a renúncia de Nixon. Além disso, Nixon tinha que lidar com o problema do Vietnã e, a partir de 1972, com escândalo do caso Watergate que apontava o envolvimento da própria Casa Branca na espionagem dos adversários políticos durante a sua campanha à reeleição. A combinação desses fatores levou à erosão do que restava de apoio à Détente nos EUA ${ }^{27}$.

Nixon e Kissinger acreditavam que se conseguissem um bom acordo com a URSS poderiam conseguir que ela pressionasse o Vietnã do Norte e assim chegar a um tratado que pusesse fim à guerra, em condições favoráveis ou no mínimo que pudessem ser aceitas pelos EUA ${ }^{28}$. Contudo, os resultados não foram os esperados, pois a pressão soviética não foi tão intensa quanto esperavam e, além disso, o Vietnã passou a receber apoio da China que disputava com a URSS a hegemonia do movimento comunista internacional. Nixon tentou estabelecer uma política triangular em que pudesse explorar as rivalidades entre a URSS e a China, mas não obteve resultados favoráveis em relação à questão do Vietnã. Porém, os resultados foram positivos na distensão com a URSS ao mesmo tempo em que secretamente os EUA iniciavam as negociações para a normalização das relações com a China. Assim, entre 1971 e 1972 os dois países chegaram a um acordo e a China foi inclusive admitida no Conselho de Segurança da ONU. Em decorrência, sentindo-se ameaçada a URSS mostrou-se mais propensa a definir os acordos com os EUA ${ }^{29}$.

Em um dos momentos mais singulares da détente, a missão espacial Apollo-Soyuz foi uma expressão das possibilidades de cooperação entre as duas superpotências. Em 1975 foram assinados os Acordos de Helsinque ${ }^{30}$. No tratado, os governos de Gerald Ford e Leonid Brejnev reconheciam a esfera soviética no Leste Europeu, mas não conseguiram chegar a bom termo em relação aos problemas dos direitos humanos cada vez mais presente na política externa dos EUA, embora em parte, de forma discursiva, uma vez que os EUA apoiavam ditaduras cruéis e haviam perpetrado infindáveis atos que poderiam ser enquadrado no campo das chamadas violências aos direitos humanos.

A era Brejnev (1964-1982) teve como um de seus pilares a convicção de que era possível igualar-se econômica e militarmente aos EUA. Isso 
implicou investimentos e decisões estratégicas que aceleraram a corrida armamentista, acentuando os desequilíbrios econômicos na URSS. A partir de 1969, os EUA também começaram a enfrentar uma crise. O Japão passou a inundar o seu mercado com carros e produtos eletrônicos, além de desbancar progressivamente a sua liderança comercial na Ásia. Os déficits orçamentários e a inflação aumentaram e o Congresso começou a efetuar cortes na verba da defesa, ao mesmo tempo em que cresciam os protestos contra a Guerra do Vietnã. Sair da guerra seria um passo importante para equilibrar o orçamento, mas para tanto era preciso um acordo com os soviéticos. Ademais, Richard Nixon e Henry Kissinger afirmaram estar dispostos a reconhecer a paridade estratégica, a não interferir na esfera de influência soviética, a cooperar na transferência de tecnologia para a URSS e, se ambas as partes chegassem a um acordo sobre o Terceiro Mundo ${ }^{31}$.

No entanto, a cada dia, a crise do Sudeste Asiático ganhava novas proporções. Os bombardeios ilegais no Camboja provocaram uma nova onda de protestos. No início de 1970, cerca de 420 unidades de ensino superior dos EUA entraram em greve. Em maio, na Kent State University, quatro estudantes foram assassinados pela Guarda Nacional. Em fevereiro de 1972, o presidente Richard Nixon visitou a China. Pretendia aproveitar a rivalidade chinesa com a URSS e neutralizá-la por meio de uma maior integração com o Ocidente, firmando um tratado de amizade e abrindo mercado para os EUA. Alguns meses depois, a China ingressou na ONU e Taiwan foi excluída. Em maio de 1972, Nixon visitou Moscou e assinou o Tratado de Limitação de Armas Estratégicas (SALT I) e acordos de cooperação comercial e técnico-científica ${ }^{32}$.

Segundo Schulzinger ${ }^{33}$, apesar dos avanços de Nixon e Kissinger na política da Détente, eles a construíram sempre em cima de segredos e sem o envolvimento dos canais diplomáticos regulares, muitas vezes com os funcionários de carreira da diplomacia a se posicionarem contra eles. Assim, quando estavam sob ataque em relação à sua política externa, não tiveram o apoio dos diplomatas. Dessa forma, a Détente, atacada a partir de diferentes flancos, ficou muito enfraquecida e estava com os seus dias contados. Após a renúncia de Nixon, Ford manteve Kissinger como secretário de Estado, mas pouco depois, em decorrência do vulto do criticismo ao antigo braço direito de Nixon, o presidente, embora o mantivesse como secretário, o exonerou do Conselho de Segurança Nacional (NSC) e, com isso, reduziu em muito o seu poder. Ao final da gestão Ford, o termo Détente estava tão desgastado nos EUA que o presidente deixou claro aos seus aliados que não mais aceitava o seu emprego. Em paralelo, as dificuldades emergidas pelas disputas entre as duas grandes potências no chamado Terceiro Mundo fez reascender as divergências entre os EUAe a URSS e teve profundas repercussões na campanha presidencial, na qual Ford tentava a sua reeleição e foi derrotado pelo candidato democrata Jimmy Carter. 
Esses processos não se davam apenas numa relação bipolar. A ascensão da Socialdemocracia na Alemanha, com uma diplomacia relativamente independente, que culminou no reconhecimento do bloco soviético, colocou novos desafios para Washington. Em certa medida, a política externa de Jimmy Carter (1977-1981) foi uma resposta a esses desafios. Uma de suas bandeiras era a defesa dos direitos humanos, vista pela URSS como uma intervenção em suas questões internas.

Paradoxalmente, essa política causava dificuldades para as ditaduras apoiadas pelos EUA (veja se a título exemplar o caso da ditadura brasileira, que levou à denúncia pelo Brasil do Acordo de Cooperação militar BrasilEUA). Outra bandeira era o projeto de governabilidade mundial da Comissão Trilateral (EUA, Europa Ocidental e Japão), fundada em 1973. Tratava-se de fazer frente à crise de acumulação capitalista, acentuada pela alta dos preços do petróleo em 1973, e manter a Europa e o Japão sob a influência dos EUA ${ }^{34}$.

No entanto, a expansão de movimentos revolucionários na África e na América Latina a partir de meados da década de 1970, a invasão do Afeganistão pela URSS, em 1979, a rejeição do SALT II pelo Senado dos EUA, a imposição de lei marcial na Polônia, em 1980, e a eleição de Ronald Reagan, em 1981, implicaram o aumento dos conflitos entre as duas potências rivais e o fim da détente.

Para Olvav Njølstad, o fim da Détente não foi um processo abrupto ou causado por um único evento. Para o autor ocorreu o gradual processo de erosão, que se deu de forma oscilatória, desde a renúncia de Nixon. $\mathrm{O}$ autor inclusive lembra que Nixon haveria dito a Brejnev pouco antes da sua saída da Casa Branca, que se a Détente fracassasse seriam os Falcões e não as Pombas que dariam as cartas nos EUA ${ }^{35}$.

Carter chegou à Casa Branca com críticas à Détente, mas ele não pensava em uma política que levasse à sua deterioração, pois pretendia promover o que ele denominou como uma Détente genuína (termo emprestado do conservador Senador Jackson que havia concorrido com ele para a nominação democrata). No entanto, desde o início da sua posse Carter se tornou impopular em Moscou, pois estava a perseguir objetivos que os soviéticos já o haviam avisado anteriormente que prejudicariam as relações entre os dois países. Em desacordo com esses encaminhamentos iniciais do novo governo dos EUA, Brejnev enviou uma mensagem secreta a Carter logo após a posse do novo presidente. Na mensagem, o líder soviético anunciava que pretendia se relacionar com os EUA com base na coexistência pacífica e em um modelo de cooperação que fosse bom para os dois lados, mas advertiu que alguns pronunciamentos públicos de Carter eram incompatíveis com esses objetivos.

Outro problema surgido logo no início do governo Carter foi a proposta de incluir no Salt II um corte mais drásticos nos arsenais nucleares. Os 
soviéticos não aceitavam a mudança e demandavam o que chamavam ser uma posição mais realista dos EUA. No entanto, Carter insistia que era possível chegar a um desarmamento real que teria como meta final o desarmamento completo da humanidade. Pela proposta cada lado teria que cortar de 20 a 25 $\%$ das suas forças, mas os soviéticos, dessa forma perderiam mais da metade dos seus mísseis de maior poder de destruição, o que era visto em Moscou como inaceitável ${ }^{36}$.

É difícil avaliar até onde a proposta de Carter se alicerçava em suas crenças religiosas e no real desejo de por fim à corrida armamentista, e com isso gerar um maior equilíbrio no orçamento do país, ou, se de fato, com esses cortes, que teriam maior impacto sobre os arsenais soviéticos, pretendia congelar a real superioridade nuclear dos EUA. Carter sabia que apoiar Dissidentes soviéticos como Sakharov ou Bukovski era considerado inaceitável por Moscou e foi exatamente isso que ele fez em 01 de março de 1977 ao receber Bukovski da Casa Branca. Esse ato, revestido de forte simbologia política e amplamente coberto pela imprensa, foi considerado uma intromissão inaceitável nos negócios internos da URSS. O embaixador Anatoli Dobrynin anotou em suas memórias que a atitude foi considerada uma tentativa de mudar o regime soviético ${ }^{37}$.

Conforme ficaram evidentes os sinais de fracasso da política da Détente Genuína, Carter voltou-se a uma política muito semelhante à que Nixon/Ford haviam implementado, e que fora por ele duramente criticada. Do lado dos EUA, aqueles que apoiavam a Détente criticaram as medidas inicialmente adotadas por Carter como perda de tempo e geradoras de conflitos que somente prejudicavam a busca de uma distensão com a União Soviética. Os setores que se opunham à Détente reafirmaram que havia ficado demonstrada a falta de vontade da URSS para negociar e de que a Détente era um caminho de mão única que só beneficiava os soviéticos. Do lado soviético, essas ações implementadas por Carter tornaram ainda mais difícil para Brejnev persuadir setores importantes da burocracia soviética sobre importância da continuidade da Détente, pois ficaram mais convencidos de que os EUA queriam interferir nas questões internas do país por meio dessa política, além de reduzir o poder militar e o status internacional do país.

De meados de 1977 em diante, houve grandes oscilações na política de distensão entre os dois países, com momentos de cooperação e momentos de conflito bastante intenso. Nesse contexto, emergiu o conflito entre a Somália e a Etiópia. Carter passou a criticar a União soviética por apoiar a Etiópia e a União soviética a criticar os EUA por apoiar o regime da Somália. A princípio, Carter manifestou dúvidas quanto ao envolvimento dos EUA na questão, pois tinha receios das ações expansionistas do ditador da Somália, Siad Barre, mas depois foi convencido por Brzezinski de que a luta no Chifre da África fazia parte da luta global dos EUA. Carter também foi alertado pelos governos aliados do 
Egito, da Arábia Saudita e do Irã de que havia uma ação expansionista soviética no Mar Vermelho e no Golfo Pérsico. Em adição Brzezinski passou a insistir que com o aumento da presença de soviéticos e cubanos na Etiópia e no Sul do Yemem, o acesso dos EUA ao petróleo do Irã e da Arábia Saudita poderia ser ameaçado.

Em maio de 1978, os Estados Unidos questionaram o ministro das relações exteriores da URSS, Andrei Gromiko sobre a presença soviética na região e ele negou que isso estivesse a ocorrer, no entanto o serviço de inteligência dos EUA possuía provas dessa presença. Carter passou a alertar os soviéticos de que essas ações poderiam abalar o futuro das relações entre os EUA e URSS. Em junho do mesmo ano Carter cobrou publicamente um posicionamento claro dos soviéticos, se desejavam a cooperação ou o confronto ${ }^{38}$.

Com o crescente de problemas com a União Soviética, a administração Carter tratou de minimizar as diferenças e com os chineses com vistas a chegar a um acordo com eles. A estratégia desenhada por Brzezinski tinha como pressuposto aproveitar a rivalidade entre os dois países e com isso, por meio da aproximação com a China, procurar levar a URSS a uma maior moderação. O anúncio de que os EUA e a China haviam estabelecido relações diplomáticas em dezembro de 1978 gerou enorme inquietação em Moscou.

Nos EUA, após a revolução iraniana, ocorrida em janeiro de 1979, ganhou força uma avaliação de que toda a região estava em risco. Em um dos cenários traçados supunha-se que o Irã poderia vir a se fragmentar e a cair na órbita soviética, o que seria um grande revés para a política dos EUA no Oriente Médio e na Ásia Central. Brzezinski alertou Carter da existência de um "arco das crises" que se não enfrentado poderia levar à constituição de uma imensa esfera de influência soviética que se estendia do Chifre da África ao Paquistão, passando pela península arábica ${ }^{39}$. Nesse contexto, Deng Xiaoping visitou os EUA. Logo depois a China invadiu parte do território do Vietnã. Em Moscou, esse processo foi interpretado como um envolvimento dos EUA em uma invasão territorial ilegal, pois se supunha que o líder chinês haveria consultado os EUA sobre o assunto ${ }^{40}$.

Todas essas tensões implicaram problemas para a conferência realizada em Viena entre Carter e Brejnev, em junho de 1979. No entanto, apesar de todos esses problemas o Salt II foi assinado em junho de 1979, em Viena, mas as desavenças entre as diplomacias dos dois países cresciam e a opinião pública nos EUA tendia a posturas mais conservadoras. Em decorrência, o tratado não foi ratificado pelo Senado (NELSON, p. 150), o que, em parte pode haver implicado uma derrota a Carter e contribuído ainda mais para desandar as relações entre as duas potências. Quando foi anunciado em dezembro de 1978 que a China e os EUA estabeleceram relações diplomáticas, as reações do Kremlim foram de extremo desagrado ${ }^{41}$. 
A Détente, segundo Njølstad ${ }^{42}$, padeceu de cinco problemas. Em primeiro lugar a falta de confiança mútua, principalmente após a renúncia de Nixon, cada lado via as ações do outro com suspeitas; porque os dois lados não possuíam valores compartilhados; porque não havia real interdependência, uma vez que a URSS tinha pouco a oferecer em termos de produtos aos EUA; porque em ambos os lados havia falta de moderação proveniente da lógica do jogo de soma zero da geopolítica da Guerra Fria; caiu como vítima da dinâmica da corrida armamentista, proveniente das pressões de militares, de grupos, de empresas, da burocracia que tinham vínculos e interesses na corrida $\operatorname{armamentista}^{43}$

Por fim, acrescenta-se a existência de divergências quanto aos eventuais resultados da pressão externa em relação aos direitos humanos na URSS e na Europa Oriental durante o período do relaxamento. À época, mesmo dissidentes que apoiavam a Détente afirmaram que ela não assegurava internamente o alargamento das liberdades democráticas. No entanto, já no início da década de 1990 especialistas no assunto avaliam que o suporte a instituições democráticas e as pressões em defesa dos direitos humanos tiveram um impacto maior do que os analistas dos EUA acreditavam à época ${ }^{44}$.

\section{NOTAS}

1FONTAINE, André. Un Seul Lit pour Deux Rêves: Histoire de la "Détente", 1962-1981. Paris: Fayard, 1981, p. 11).

2 Ibidem, p. 12; Ver também: FONTAINE, André. Histoire de la Guerre Froide. Paris: Fayard, 1967, Tome II.

3 WHITE, Brian. Britain, Détente, and Changing East-West Relations. London/New York: Routledge, 1992.

4 Ibidem, p. 21.

5 NELSON, Keith. The making of Détente: Soviet-American relations in the shadow of Vietnam. Baltimore: John Hopkins University Press, 1995, p. 154.

6 JACKSON, Ian. The Cold War: the Western European perspective In: LARRES, Klaus (Ed.). A Companion to Europe Since 1945. Malden/Oxford: Wiley-Blackwell, 2009, p. 4766.

7 MUNHOZ, Sidnei J.; GONÇALVES, José Henrique Rollo. Détente. In: Enciclopédia de guerras e revoluções do século $X X$ : as grandes transformações do mundo contemporâneo. Rio de Janeiro, 2004, p. 217-219. 8 Ibidem.

9 Ibidem.

10 Ibidem.

11 HANHIMÄKI. Détente in Europe 1962-1975. In: LEFFLER, Melvyn; WESTAD, ODD A. The Cambridge History of the Cold War. London: Cambridge University Press, 2010, v. 2, p. 198-218. 
12 Ibidem, p. 199-200.

13 Ibidem, p.201

14 HALLIDAY, Fred. The Making of the Second Cold War. London: Verso, 1983.

15 BOZO, Frédéric. France "Gaulism" and the Cold War".In: LEFFLER, Melvyn; WESTAD, ODD A. The Cambridge History of the Cold War. London: Cambridge University Press, 2010, v. 2, p. 159.

16 Ibidem, 2010, p. 165-166.

17 LINDLEY-FRENCH, Julian; MACFARLANE, Neil. The North Atlantic Organization: the enduring Alliance, London: Routledge, 2007, p. 20-21.

18 BOZO, Frédéric. France "Gaulism" and the Cold War".In: LEFFLER, Melvyn; WESTAD, ODD A. The Cambridge History of the Cold War. London: Cambridge University Press, 2010, v. 2, p. 166-167.

19 HANHIMÄKI. Détente in Europe 1962-1975. In: LEFFLER, Melvyn; WESTAD, ODD A. The Cambridge History of the Cold War. London: Cambridge University Press, 2010, v. 2, p. 203

20 Ibidem, p. 203.

21 ARMS, Thomas. Encyclopedia of the Cold War. New York: Facts on File, 1994, p.448.

22 SCHULZINGER, Robert D. Détente in the Nixon-Ford years, 1969-1976. In:

LEFFLER, Melvyn P.; WESTAD, Odd Arne. The Cambridge History of the Cold War. Cambridge: Cambridge University Press, 2010, v.2, p. 375.

23 NJØLSTAD, Olav. The collapse of superpower détente, 1975-1980. In: LEFFLER, Melvyn P. ; WESTAD, Odd Arne. The Cambridge History of the Cold War. Cambridge: Cambridge University Press, 2010, v.3, p. 137.

24 SCHULZINGER, Robert D. Détente in the Nixon-Ford years, 1969-1976. In: LEFFLER, Melvyn P.; WESTAD, Odd Arne. The Cambridge History of the Cold War. Cambridge: Cambridge University Press, 2010, v.2, p. 374

25 McCORMICK, Thomas J. Americas's Half-Century: United States Foreign Policy in the Cold War and After. Baltimore : The John Hopkins Press, 1995, $2^{\circ}$ ed.

26 NJØLSTAD, Olav. The collapse of superpower détente, 1975-1980. In: LEFFLER, Melvyn P. ; WESTAD, Odd Arne. The Cambridge History of the Cold War. Cambridge: Cambridge University Press, 2010, v.3, p. 139.

27 SCHULZINGER, Robert D. Détente in the Nixon-Ford years, 1969-1976. In: LEFFLER, Melvyn P.; WESTAD, Odd Arne. The Cambridge History of the Cold War. Cambridge: Cambridge University Press, 2010, v.2.

28 McCORMICK, Thomas J. Americas's Half-Century: United States Foreign Policy in the Cold War and After. Baltimore : The John Hopkins Press, 1995, $2^{\circ}$ ed.

29 SCHULZINGER, Robert D. Détente in the Nixon-Ford years, 1969-1976. In: LEFFLER, Melvyn P.; WESTAD, Odd Arne. The Cambridge History of the Cold War. Cambridge: Cambridge University Press, 2010, v.2, p. 377-378

30 MUNHOZ, Sidnei J.; GONÇALVES, José Henrique Rollo. Détente. In: Enciclopédia de guerras e revoluções do século $X X$ : as grandes transformações do mundo contemporâneo. Rio de Janeiro, 2004. 
31 McCORMICK, Thomas J. Americas's Half-Century: United States Foreign Policy in the Cold War and After. Baltimore : The John Hopkins Press, 1995, $2^{\circ}$ ed.

32 MUNHOZ, Sidnei J.; GONÇALVES, José Henrique Rollo. Détente. In: Enciclopédia de guerras e revoluções do século $X X$ : as grandes transformações do mundo contemporâneo. Rio de Janeiro, 2004.

33 SCHULZINGER, Robert D. Détente in the Nixon-Ford years, 1969-1976. In: LEFFLER, Melvyn P.; WESTAD, Odd Arne. The Cambridge History of the Cold War. Cambridge: Cambridge University Press, 2010, v.2.

34 MUNHOZ, Sidnei J.; GONÇALVES, José Henrique Rollo. Détente. In: Enciclopédia de guerras e revoluções do século $X X$ : as grandes transformações do mundo contemporâneo. Rio de Janeiro, 2004.

35 NJØLSTAD, Olav. The collapse of superpower détente, 1975-1980. In: LEFFLER, Melvyn P. ; WESTAD, Odd Arne. The Cambridge History of the Cold War. Cambridge: Cambridge University Press, 2010, v.3, p. 155)

36 Ibidem, p. 144.

37 Ibidem, p144-145.

38 Ibidem, p.147.

39 VIZENTINI, Paulo F. Oriente Médio e Afeganistão: um século de conflitos. Porto Alegre: Leitura XXI, 2002, p.62.

40 NJØLSTAD, Olav. The collapse of superpower détente, 1975-1980. In: LEFFLER, Melvyn P. ; WESTAD, Odd Arne. The Cambridge History of the Cold War. Cambridge: Cambridge University Press, 2010, v.3, p148.

41 Ibidem, p. 148.

42 Ibidem.

43 Ibidem, p.153-154.

44 WELLS Jr, SAMUEL F., Nuclear weapons and European security. In HOGAN, Michael. The end of the Cold War. Its Meaning and Implications, Cambridge (Mass): Cambridge University Press, 1996, p. 66.

\section{REFERÊNCIAS BIBLIOGRÁFICAS}

COATS, Ken (ed.) O conflito Leste-Oeste: uma discussão com Roy Medvedev. Lisboa: Livros do Brasil, s.d.

HOGAN, Michael J. (Ed.). America in the world: the historiography of American foreign relations since 1941. New York: Cambridge University Press, 1995.

KISSINGER, Harry. Diplomacy. New York: Touchstone, 1994.

LaFEBER, Walter. America, Russia and the Cold War: 1945-1996. New York: McGrawHill, 1997.

LEFFLER, Melvyn P. ; WESTAD, Odd Arne. The Cambridge History of the Cold War.

Cambridge: Cambridge University Press, 2010, v.2, p. 258-280

PAINTER, David. The Cold War: an international history. London: Routledge, 1999. (The Making of the Contemporary World)

PATERSON, Thomas G.; MERRIL, Dennis (Ed.). Major Problems in American Foreign Relations, vol. II: since 1914. Documents and Essays. Lexington: D.C. Heath, 1989. 
Revista Esboços, Florianópolis, v. 21, n. 32, p. 138-158, out. 2015.

RUBINSTEIN, Alvin. Soviet Foreign Policy since World War II: Imperial and Global. Boston: Little Brown, 1981.

Artigo recebido em janeiro de 2015. Aceito em maio de 2015. 